Article available at nttp://Www.parasite-Journal.org or nttp://dx.dol.org/10.1051/parasite/200708s2126

\title{
ASSESSMENT OF EFFICACY AND SAFETY OF VARIOUS ADJUVANT FORMULATIONS WITH A TOTAL SOLUBLE EXTRACT OF TRICHINELLA SPIRALIS
}

\author{
AUCOUTURIER J.,** DEVILLE S.,**, PERRET C.**, VALLÉE I.** \& BOIREAU P.**
}

\section{Summary :}

Trichinellosis, a re-emerging zoonosis in several countries and pig, is the main species responsible for its transmission to human. Vaccination of swine could be an alternative to prevent the risk of human contamination. In order to develop an efficient and safe inactivate vaccine, the choice of the adjuvant is an important issue. The aim of this study was to develop and select potent and safe adjuvants by screening them in an experimental model with a crude soluble antigen from LI muscular larvae (ML) of Trichinella spiralis (Ts). The efficacy was checked by the quantification of specific antibody levels. Specific and non-specific lgE antibody levels were also assessed. Safery was checked by the assessmen of the local reaction at the injection site.

Various Montanide ${ }^{\circledR}$ ISA adjuvant formulations including water in oil, oil in water and multiphasic emulsions, but also nanoparticles or microbeads were tested. The results clearly showed differences between the antibody responses induced by the adjuvants and demonstrated the necessity to use an adjuvant to obtain a specific $\lg G(\lg G 1$ or $\lg G 2 a)$ response directed against the total soluble extract of Ts. All the formulations enhanced the humoral immune response. The origin of the oil contained in the emulsions played an important role on the efficacy. Indeed emulsions based on mineral oils were more efficient than those based on metabolisable oils. However it was linked with stronger local reactions. Multiphasic and oil in water emulsions but also nanoparticles failed to induce lgG2a antibody levels. Microbeads and water in oil formulations based on mineral oils were more efficient. This experimentation allowed then the selection of several adjuvants which efficacy will be further investigated by a challenge test and an analysis of the cellular populations involved in the mechanism of the immune response.

KEY WORDS : adjuvants, Montanide ${ }^{\circledR}$, emulsions, nanoparticules, Trichinella, immunisation.

T Trichinellosis is a food borne parasitic disease transmitted by the nematode Trichinella spiralis (Ts). It is a re-emerging zoonosis in several countries and pig is the main species responsible for its transmission to humans (review: Boireau et al., 1999). In order to eradicate the disease, improvement of breeding conditions and controls of the animals entering the food chain is an important parameter. Chemical treatment with anti-helminthic in food for swine

* SEPPIC, 75, Quai d'Orsay, 75321 Paris cedex 07, France.

** UMR BIPAR INRA-AFSSA-ENVA, 7, avenue du Général de Gaulle, 94704 Maisons-Alfort, France.

Correspondence: J. Aucouturier

Tel : 33-1-40-62-51-74 - Fax : 33-1-40-62-52-53.

E-mail : jerome.aucouturier@airlique.com can be also a way to control the disease however in several cases these drugs are not effective or safe enough and some risks of resistance against the parasites can occur. Vaccination is a good alternative. Veterinary vaccines against parasites are mostly attenuated live vaccines as the culture of parasites is time consuming and costly, rendering difficult the development of inactivated vaccine. So the development of recombinant antigen can be a good alternative. However the complexity of the life cycle, the wide variety of antigens is also a concern to get efficient vaccines. Moreover as purified, recombinant or synthetic antigens are less immunogenic, they will require the use of potent and safe adjuvants. The choice of the adjuvant must be done according to various criteria in order to improve the immune response against the parasite and the protection, without inducing local or general reactions. Beyond these criteria most important are the type of immune response, the duration of immunity, the target species, the quality and the origin of the antigens, and the route of immunization (Aucouturier et al., 2001).

Aluminium hydroxide and emulsions are the most currently adjuvants used in veterinary vaccines. Water in oil emulsions are potent adjuvant and induce a strong and long term immune response (Bahnemann et al., 1987). Some of them can enhance cellular immunity (Mahan et al., 1998; Martinez et al., 1997). Water in oil in water emulsions enhance strong, and both long and short term immunity and are well tolerated (Salt et al., 1998). Oil in water emulsion enhance strong and short term immunity and are well tolerated (Lizon et al., 1992). These emulsions can be based on mineral, non mineral oil or a mix of them.

In the case of trichinellosis some vaccination trials have been achieved successfully in mice with crude antigen associated with Freund complete adjuvant (FCA) (Raefa et al., 1996; Robinson et al., 1995; Sun et al., 1994), but very few have been performed in swine (Marti et al., 1987) and none with recombinant proteins and other type of adjuvants (Robinson et al., 1994).

The aim of this study was then to develop and select potent and safe adjuvants, first by screening them in an experimental model with a crude soluble antigen 
from L1 muscular larvae (ML) of Trichinella spiralis. The efficacy was checked by the quantification of specific antibody levels. IgG1 and IgG2a antibody titers gave respectively an information on the ability of the adjuvants to enhance humoral and cellular responses. Specific and non-specific IgE antibody levels were also assessed as it is an important isotype induced during trichinellosis. Safety was checked by the assessment of the local reactions at the injection site.

\section{MATERIAL AND METHODS}

\section{ANIMALS}

G roups of five female OF1 mice (IFFA-CREDO) -weighting 18-20 g were vaccinated with a crude soluble antigen of Ts from L1 ML. Antigen concentration has been previously optimised at $5 \mu \mathrm{g} /$ dose in order to observe the best adjuvant effect. This best adjuvant effect is defined as the antigenic concentration which gives the highest immune response when combined with an adjuvant but gives no immune response when administered without adjuvant. The adjuvant chosen was a water in oil emulsion similar to incomplete Freund adjuvant but less viscous and better tolerated.

\section{FORMULATIONS}

Three groups of adjuvants were tested. 1) Ready to use adjuvants (Montanide ${ }^{\circledR}$ ISA, SEPPIC, Paris, France) were combined in various ways with antigenic phase in order to produce different kinds of emulsions, water in oil (W/O), water in oil in water (W/O/W), or oil in water (O/W) (Table I); 2) Several liquid nanoparticles containing a very low quantity of oil (Montanide ${ }^{\circledR}$ IMS,

\begin{tabular}{lccc}
\hline & \multicolumn{1}{c}{ Mineral } & $\begin{array}{c}\text { Mineral } \\
+ \text { non mineral }\end{array}$ & Non mineral \\
\hline W/O & Montanide ISA70 & Montanide ISA775 & Montanide ISA763A \\
$(70 / 30)^{*}$ & & & \\
W/O/W & Montanide ISA206 & Montanide ISA264 & Montanide ISA207 \\
$(50 / 50)^{*}$ & & & \\
O/W & Montanide ISA25 & Montanide ISA28 & Montanide ISA35 \\
$25 / 75)^{*}$ & & & \\
\hline
\end{tabular}

* Oil phase/Ag phase (weight/weight).

Table I. - Composition of the different ranges of Montanide ${ }^{\circledast}$ ISA according to the type of emulsion and the nature of the oil.
SEPPIC, Paris, France) have been also assessed (Table II). They combine the adjuvant effect of nanoparticles with a new immunostimulant; 3) Microbeads are solid particles of $1 \mu \mathrm{m}$ on which antigen is adsorbed.

\section{VACCINATION}

Fourteen adjuvants were tested and compared to a control group of five mice, which were vaccinated without adjuvant. A dose of $100 \mu \mathrm{l}$ of vaccine formulation was administered subcutaneously at day 0 (D0) and a boost was performed on D28.

\section{TITRATION OF ANTIBODIES IN MICE SERA}

Blood samples were taken on D0, D14, D28, D42, D56, D90 and specific IgG1, IgG2a, IgE antibody levels in pool of sera were assessed by an indirect ELISA technique. IgG1/IgG2a titration: 96 well plates were coated with $2 \mu \mathrm{g}$ in 0.05 sodium carbonate buffer ( $\mathrm{pH} 9.6)$ per well and incubated for two hours at $37^{\circ} \mathrm{C}$. The plates were washed three times with PBS/Montanox ${ }^{\circledR} 20$ (Polysorbate20, SEPPIC) $0.05 \%$. Then, they were incubated with a blocking solution ( $5 \%$ swine gelatin (Prolabo), $0.05 \%$ Montanox $^{\circledR} 20$ in PBS) during 30 minutes at $37^{\circ} \mathrm{C}$. The samples were diluted $1: 10,1: 100$ or $1: 1,000$ and $100 \mu \mathrm{l}$ were added in the first raw and a 1:2 serial dilution in blocking solution was then performed for each sample. Plates were then incubated for one hour at $37^{\circ} \mathrm{C}$ and washed three times. One hundred $\mu \mathrm{l}$ of peroxidase conjugated goat anti-mouse IgG1 or IgG2a (TEBU) diluted 1:6,000 in blocking solution were added and the plates were incubated for one hour at $37^{\circ} \mathrm{C}$. The peroxidase activity was revealed with OPD $1 \mathrm{mg} / \mathrm{ml}$ (O-phenylenediamine, SIGMA), stopped with $\mathrm{H}_{2} \mathrm{SO}_{4}(12.5 \%)$ and read at $492 \mathrm{~nm}$.

IgE titration: 96 well plates coated with $2 \mu \mathrm{g} / \mathrm{ml}$ of rat IgG1 anti-mouse IgE antibody (clone R35-72, Pharmingen BD) in PBS ( $\mathrm{pH}$ 7.2-7.4). Plates were incubated for one hour at $37^{\circ} \mathrm{C}$, then overnight at $4^{\circ} \mathrm{C}$ and finally washed three times with PBS/Montanox ${ }^{\circledR}$ (polysorbate20 SEPPIC) $0.05 \%$. The plates were incubated 30 minutes at room temperature (RT) with a blocking solution (BSA $1 \%$, in PBS). Samples were diluted 1:10, 1:100 or 1:1000 and $100 \mu \mathrm{l}$ were added in each well. Plates were then incubated for one hour at RT and washed three times. One hundred $\mu \mathrm{l}(2 \mu \mathrm{g} / \mathrm{ml})$ of biotinylated rat anti-mouse IgE antibody (clone R3582,

\begin{tabular}{llll}
\hline & \multicolumn{1}{c}{ Mineral } & Mineral + non mineral & Non mineral \\
\hline & $<50 \mathrm{~nm}$ & $50-200 \mathrm{~nm}$ & $200-500 \mathrm{~nm}$ \\
Nanoparticles & Montanide IMS 3011 & Montanide IMS 1111 & Montanide IMS 2211 \\
$(50 / 50)^{*}$ & & Montanide IMS 1311 & \\
\hline
\end{tabular}

* Adjuvant phase/Ag phase ( $\mathrm{vol} / \mathrm{vol})$.

Table II. - Composition of the different ranges of Montanide ${ }^{\circledR}$ IMS according to the size of particles. 
Pharmingen BD) were added and plates were incubated for one hour at RT. After three washing, $100 \mu \mathrm{l}$ streptavidin-biotin-peroxidase were added (Pharmingen $\mathrm{BD}$, dilution 1:1000). Plates were incubated for $30 \mathrm{minu}-$ tes at RT. After six washings the peroxidase activity was revealed with ABTS (2, 2'-azinobis-3-ethylbenzthiazoline-sulfonic acide- SIGMA) and read at $405 \mathrm{~nm}$.

\section{ASSESSMENT OF LOCAL REACTION}

Intensity of local reaction is defined according to the following schedule: 0 : no local reactions; 1 : small local reactions less than $1 \mathrm{~mm}$; 2 : small local reactions less than $5 \mathrm{~mm}$; 3: local reactions less than $1 \mathrm{~cm}$; 4 : local reactions exceeding $1 \mathrm{~cm}$.

\section{RESULTS}

0 efore the boost, a strong adjuvant effect was observed on IgG1 antibody response with all formulations. However some differences were noticed. With emulsions the origin of the oil influenced the immune response. Indeed those based on mineral oils induced a stronger immune response than emulsions based on non mineral oils. Nanoparticles with a size between 50 and $200 \mathrm{~nm}$ induced the best immune response (Fig. 1).

IgG2a antibody responses depended strongly on the origin of the oil but also from the type of emulsion. $\mathrm{W} / \mathrm{O}$ were more efficient than $\mathrm{O} / \mathrm{W}$, themselves more potent than $\mathrm{W} / \mathrm{O} / \mathrm{W}$ emulsions. Microbeads elicited as well an important IgG2a antibody response (Fig. 2).
The booster vaccination strongly enhances IgG1 antibody titers elicited by the various adjuvants and even three months after priming, a strong immune response was maintained with adjuvanted groups (Fig. 3). Water in oil emulsion based on mineral oils remained the most efficient formulations to enhance IgG2a antibody response as well as microbeads that were characterized by slow decrease after three months (Fig. 4).

No specific IgE antibodies have been detected. Some formulations enhanced the total IgE antibodies but there was no correlation with the type of formulation or the origin of the oil. Interestingly, according to the type of formulation, the time for which the induction of total IgE occurred was different (Fig. 5).

Concerning safety, local reactions observed were granuloma or oil deposit. Emulsions based on non mineral oil were better tolerated than mineral oil based adjuvants. $\mathrm{O} / \mathrm{W}$ formulations induced the strongest local reactions, and nanoparticles were well tolerated (Fig. 6).

\section{DISCUSSION}

The development of a vaccine against trichinellosis is one solution to avoid the risk of food

1 borne contamination, but few vaccination studies have been so far achieved. This can be partly explained by the complexity of the parasite cycle and the wide variety of immunogens (Eloit et al., 1997). Most of vaccination trials have been performed in mice or pigs with total soluble extract or excretorysecretory component generally associated with Freund

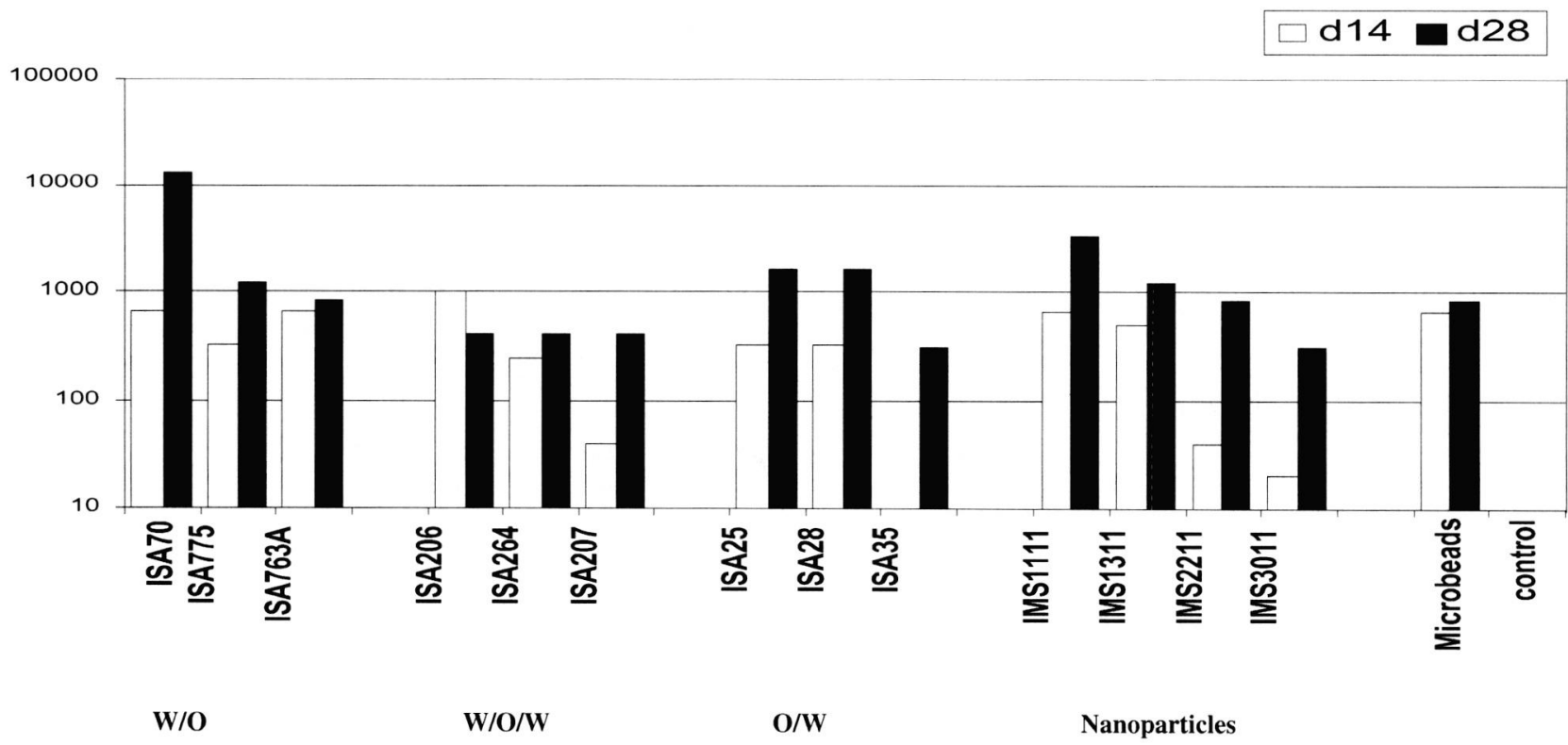

Fig. 1. - Specific IgG1 antibody titer after primovaccination. Formulation of Montanide ${ }^{\circledR}$ ISA and Montanide ${ }^{\circledR}$ IMS and grouped by type of formulations: W/O, W/O/W, O/W, nanoparticles and microbeads. The titers are expressed by the inverse of the last positive dilution in ELISA. This figure give the result of ELISA performed on pools of six mice sera collected on day 14 and 28. 


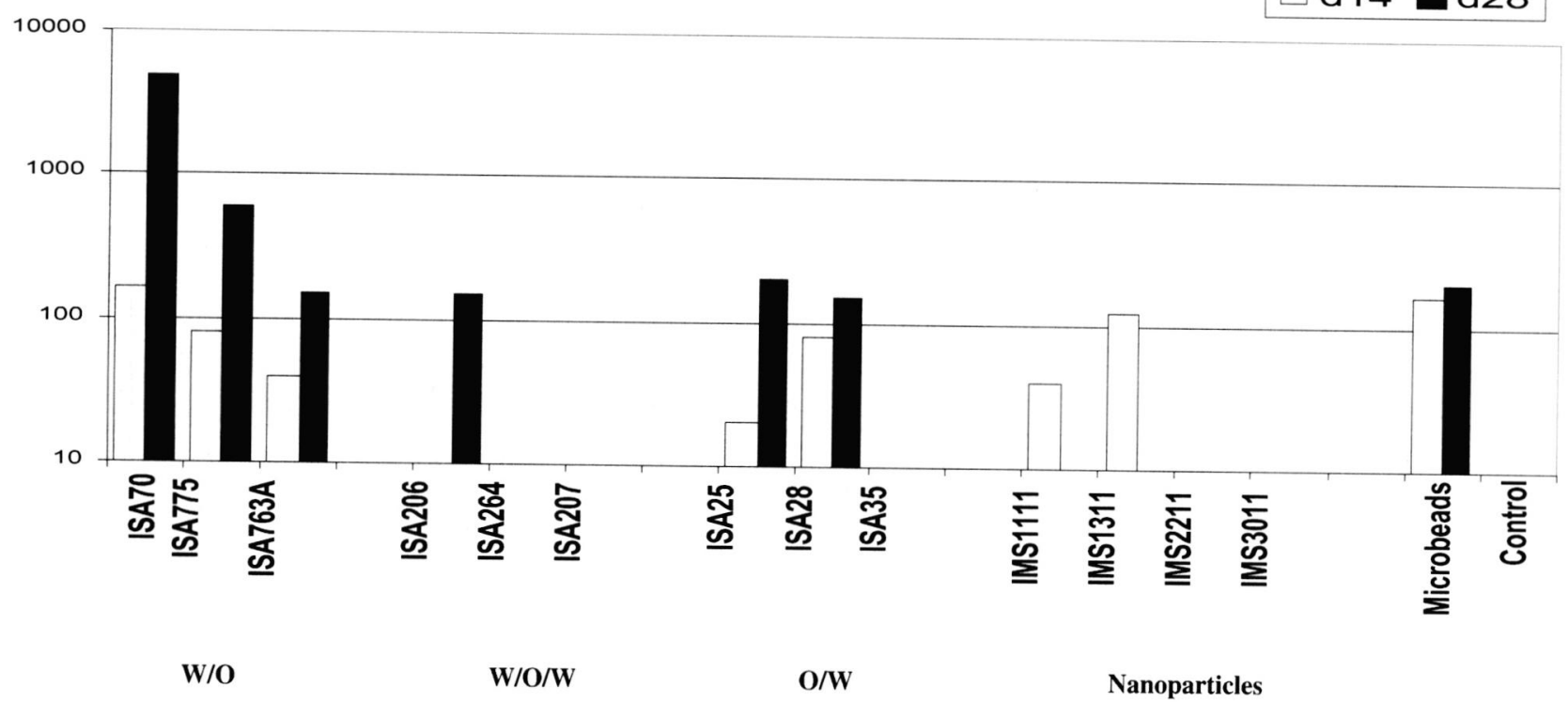

Fig. 2. - Specific IgG2a antibody titer after primovaccination. Formulation of Montanide ${ }^{\circledR}$ ISA and Montanide ${ }^{\circledR}$ IMS are grouped by type of formulations: $\mathrm{W} / \mathrm{O}, \mathrm{W} / \mathrm{O} / \mathrm{W}, \mathrm{O} / \mathrm{W}$, nanoparticles and microbeads. The titers are expressed by the inverse of the last positive dilution in ELISA. This figure give the result of ELISA performed on pools of six mice sera collected on day 14 and 28.

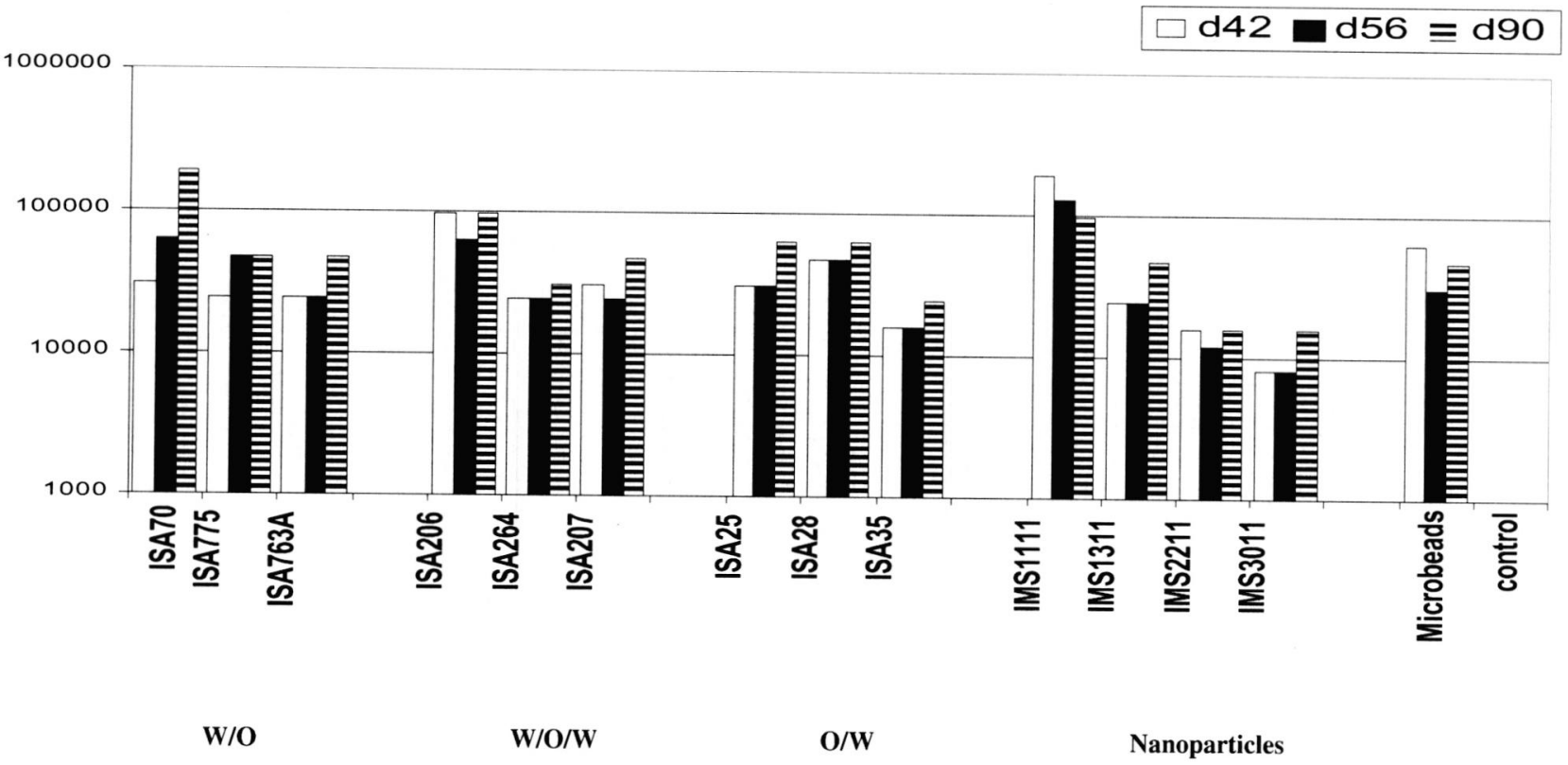

Fig. 3. - Specific IgG1 antibody titer after boost. Formulation of Montanide ${ }^{\circledR}$ ISA and Montanide ${ }^{\circledR}$ IMS are grouped by type of formulations: $\mathrm{W} / \mathrm{O}, \mathrm{W} / \mathrm{O} / \mathrm{W}, \mathrm{O} / \mathrm{W}$, nanoparticles and microbeads. The titers are expressed by the inverse of the last positive dilution in ELISA. This figure gives the result of ELISA performed on pools of six mice sera collected on day 42,56 and 90 . 
$\square \mathrm{d} 42 \square \mathrm{d} 56 \equiv \mathrm{d} 90$

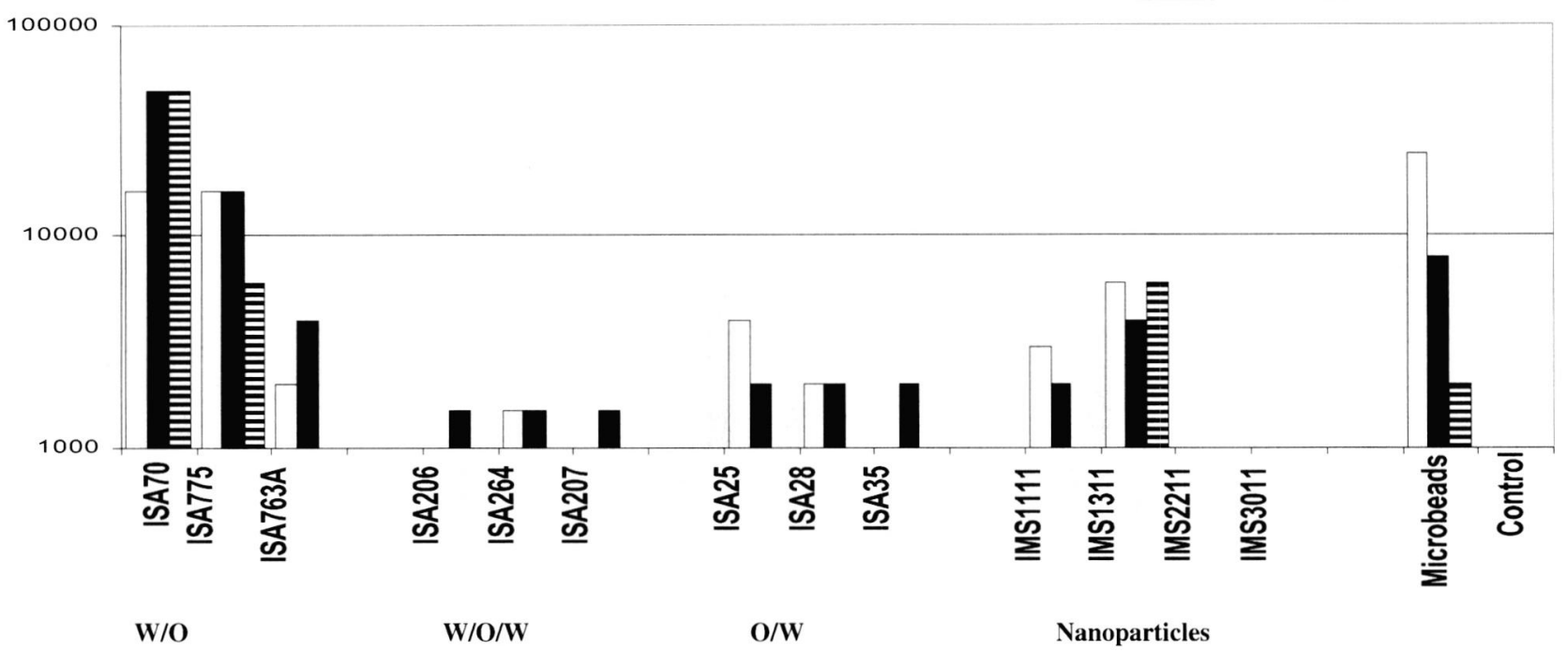

Fig. 4. - Specific IgG2a antibody titer after boost. Formulation of Montanide ${ }^{\circledR}$ ISA and Montanide ${ }^{\circledR}$ IMS are grouped by type of formulations: $\mathrm{W} / \mathrm{O}, \mathrm{W} / \mathrm{O} / \mathrm{W}, \mathrm{O} / \mathrm{W}$, nanoparticles and microbeads. The titers are expressed by the inverse of the last positive dilution in ELISA. This figure gives the result of ELISA performed on pools of six mice sera collected on day 42,56 and 90 .

$\square 7 \square 28 \quad \boxminus 42 \otimes 56 \square 90$

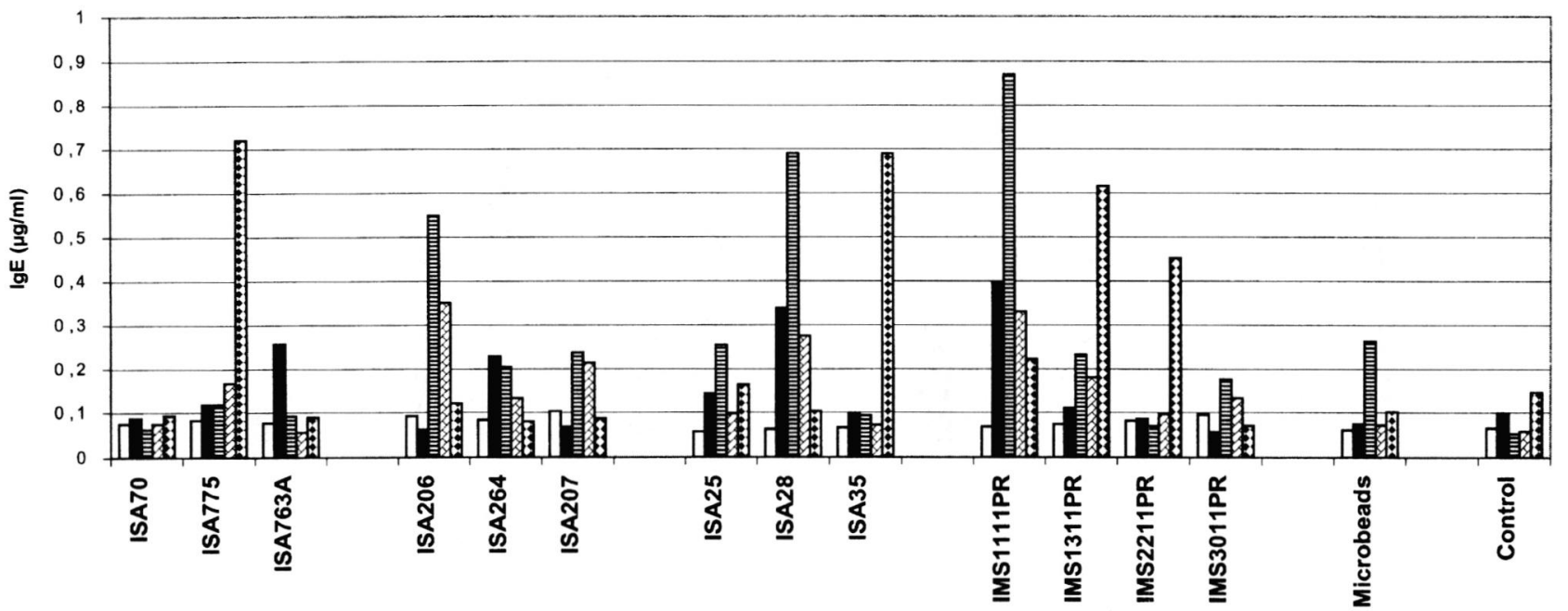

W/O W/O/W $\quad$ O/W $\quad$ Nanoparticles

Fig. 5. - Non specific IgE antibody titer, before and after boost. Titers are expressed in $\mu g$ of antibody by $\mathrm{ml}$ of sera. 


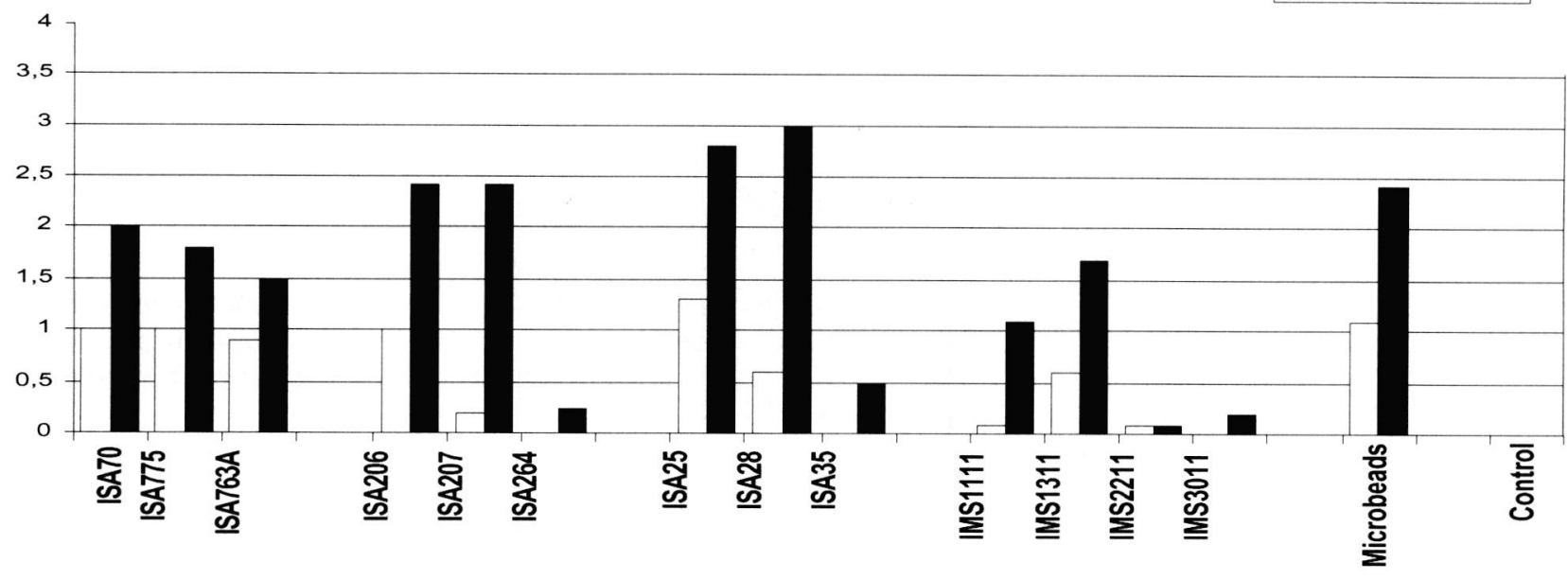

W/O

W/O/W

O/W

Nanoparticles

Fig. 6. - Local reactions. Formulation of Montanide ${ }^{\circledR}$ ISA and Montanide ${ }^{\circledR}$ IMS are grouped by type of formulations: W/O, W/O/W, O/W, nanoparticles and microbeads. Intensity of local reaction is defined according to the following schedule: 0: no local reactions; 1 : small local reactions less than $1 \mathrm{~mm} ; 2$ : small local reactions less than $5 \mathrm{~mm}$; 3 : local reactions less than $1 \mathrm{~cm}$; 4 : local reactions more than $1 \mathrm{~cm}$. This figure gives the result of data on day 7 and day 35 .

complete adjuvant (FCA) (Raefa et al., 1996; Robinson et al., 1995; Sun et al., 1994). A strong immune response and a good protection against challenge was obtained, however the use of FCA is unacceptable due to its toxicity, which led to the carcass blemish and a discomfort of the animals. Then the selection of a potent and safe adjuvant is an issue. In this experiment we have assessed various adjuvants already use in veterinary vaccines or which have proved their safety in target species. These adjuvants were tested for their ability to induce a strong antibody response. IgG1 and IgG2a subclasses were also checked in order to defined their ability to influence the humoral or cellular immune responses as this latter is important to get a good protection.

The results clearly demonstrate that all the adjuvants formulations allowed the induction of a strong immune response when compared to the control group immunized without adjuvant. The most potent adjuvants were $\mathrm{W} / \mathrm{O}$ emulsions. Those based on mineral oil induced the highest IgG2a antibody levels. Other types of emulsions based on mineral oil induced low IgG2a titers. The quality of the immune response was thus linked to the type of emulsion and the origin of the oil. It has been already demonstrated that W/O emulsion based on mineral oil were able to induce a cellular immunity in a parasitic model (Cowdria ruminantum) (Mahan et al., 1998; Martinez et al., 1997). The interaction of the antigen with emulsions droplets could explain a modification in the processing of this antigen (Rimmelzwaan et al., 1997). The microbeads constitute a new category of adjuvants. They appeared in this study to enhance powerfully IgG1 and IgG2a antibody titers.

We were not able to detect IgE antibody specific for Ts antigens, but it is important to note that the ELISA test was performed on sera samples taken 14 days after immunization and should be checked earlier in further studies. W/O and microbeads did not enhance total IgE synthesis. This characteristic could be an advantage if we consider that induction of total IgE can dilute specific IgE antibody level.

Safety of the adjuvant is also a concern, especially if the target species is a sensitive animal like swine. The safety depends on various parameters. In the case of emulsion the origin of the oil is important. Mineral oil are less tolerated than non mineral oil but more efficient. The type of emulsion is also important. The quality of the antigen have a strong impact on the safety of the vaccine formulation and crude inactivated extract induce generally strong local reactions which can be amplified by the presence of an adjuvant. On contrary the recombinant proteins, purification of antigens or decrease concentration can reduce the local reactions.

In our experiment the most tolerated adjuvants were not the most efficient. Therefore the choice will be a balance between safety and efficacy. W/O based on a mix of mineral and non mineral oil (Montanide ${ }^{\circledR}$ ISA775) seemed to encompass these criteria. 


\section{CONCLUSION}

B ased on these observations W/O (Montanide ${ }^{\circledR}$ ISA 70, Montanide ${ }^{\circledR}$ ISA 775, Montanide ${ }^{\circledR}$ ISA 763A) emulsions and microbeads will be tested in further experiments to check their ability to improve protection against challenge. An interesting complementary experiment could be also achieved by assessing the immunodominant protein of the total soluble extract by western blot with the sera of the mice vaccinated with the different formulations. This could determine if the protein recognized by the antibodies are the same according to the adjuvant used.

\section{REFERENCES}

Aucouturier J., Dupuis L. \& Ganne V. Adjuvants designed for veterinary and human vaccines. Vaccine, 2001, in press.

Bahnemann H.G. \& Mesquita J.A. Oil adjuvant vaccine against foot-and-mouth disease. Bol. Centr. Panam. Fiebre Aftosa, $1987,53,25-30$.

Boireau P., Perret C. \& Fabien J.F. La trichinellose : une zoonose parasitaire persistante. Journal de l'Académie Vétérinaire, 1999, 72, 105-114.

Eloit M. Benet J.J. \& Bourdeau P. Epidemiology of infections and parasitic infestations. Pastoret P.P., Blancou J., Vannier P. \& Verschueren (eds). Veterinary Vaccinology, 1997, 113-129.

Lizon I. \& Trouve G. New safe and efficient oil adjuvants for veterinary vaccines. 12th I.P.V.S. Congress, The Hague, Netherlands, 1992 , August 17-20 ${ }^{\text {th }}$.

Mahan S.M., Kumbula D., Burridge M.J. \& Barbet A.F. The inactived Cowdria ruminantium vaccine for heartwater protects against heterologous strains and against laboratory and field tick challenge. Vaccine, 1998, 16 (11/12), 1203-1211.

Marti H.P. Murrell K.D. \& Gamble H.R. Trichinella spiralis: immunization of pigs with newborn larval antigens. Experimental parasitology, 1987, 63, 68-73.

Martinez D., Totte P., Perez J.M., Trap J., Kamau J., Sheikboudou C., Vachiery N., Mackeever D. \& Bensaid A. Analysis of peripheral blood mononuclear cell population in cattle and goats immunized with killed Cowdria ruminantum in oil adjuvant by flow cytometry. Proceeding of the $4^{\text {th }}$ biennal meeting of the STVM. Montpellier France, 1997, May 5-9 .

RaEFa A.D., Magda M.S. \& SOAD M.Y. Immunization against Trichinella spiralis using antigens from different life cycle stages. Experimental study in mice. J. Egypt. Soc. Parasitol., 1996, 26 (1), 19-26.

RimmelzwaAn G.F. \& Osterhaus A.D.M.E. The immune response. Pastoret P.P., Blancou J., Vannier P. \& Verschueren Editors. Veterinary vaccinology, 1997, 55-67.

Robinson.T., Bellaby T. \& Wakelin D. Oral and parenteral vaccination against Trichinella spiralis infections in high and low responder mice. International Journal of Parasitology, 1995, 25 (8), 989-992.
Robinson.T., BELLABY T. \& WAKELIN D. Vaccination against the nematode Trichinella spiralis in high and low responder mice. Effect of different adjuvants upon protective immunity and immune responsiveness. Immunology, 1994, 82, 261-267.

Salt J.S., Barnett P.V., Dani P. \& Williams L. Emergency vaccination of pigs against foot-and-mouth disease: protection against disease and reduction in contact transmission. Vaccine, 1998, 16 (7), 746-754.

Sun S., Xu W., He N. \& Sugane K. An antigenic recombinant fusion protein from Trichinella spiralis induces a protective response in Balbc/mice. Journal of Helminthology, 1994, 68, 89-91. 